categorizes the types of learning that result from process drama, suggests ways that learning might be assessed, and creates a set of learning objectives.

However, even though her book deals specifically with drama in a same-sex class, it also speaks to all educators about issues such as the role of the teacher, experiential learning, assessment, and, perhaps most significantly, how the theory of knowledge as a construct might translate into classroom practice. It is ironic that the form of drama Gallagher so eloquently describes needs to be experienced, or at least seen, to be fully appreciated. While this book will be a valuable addition to the shelves of drama teachers who have worked in process drama, one hopes it will also inspire others to experience this form first-hand, so that they, too, might imagine the possibilities.

Jane E. Powell

University College of the Cariboo

\title{
Gary McCulloch and William Richardson. Historical Research in Educational Settings. Buckingham and Philadelphia: Open University Press, 2000. Pp. 154.
}

The virtue of Historical Research in Educational Settings is that it accomplishes, in brief fashion, exactly what it advertises in the introduction. It serves as a useful handbook for the novice researcher intending to incorporate history as part of their studies, and for the "seasoned campaigner" as well. The reader is advised that the "researcher experienced in education may be new to history, and, similarly, that those experienced in history may be new to education” (p. 1). Thus, the book is aimed at a potentially broad and diverse audience: educationists seeking to incorporate historical methods; historians seeking insight into how to relate their training to education; and those with a social science background seeking to "develop both their historical awareness and their sensitivity to educational issues” (p. 4). The 
text is a part of a series published by the Open University Press, edited by Pat Sikes, entitled Doing Qualitative Research in Educational Settings.

The authors express concern at the erosion of the institutional base the history of education once had, at its zenith in the 1960s and '70s. With this in mind, they argue that it is particularly important to review recent developments in the area, reassess key issues and methodology, and look to the future of the discipline.

The layout of the text is effective either for reading straight through or, more likely, for use as a reference. The chapters include several case studies as effective illustrative devices. The opening chapter offers a section on "thinking historically" in educational settings, which serves as a useful introduction to the field for those unfamiliar to the territory. The first case study included in this chapter is entitled "Historical research on the school curriculum and classroom" and includes a brief historiographical survey, ranging from Kliebard (1996) to Ariès (1960).

Chapter Two is concerned with the treatment of the history of education in recent texts dealing with research methods in education and in various introductions to historical research. The limitations of both are highlighted. In the case of the former, the authors argue that texts have failed to provide a "balanced and considered introduction for students wishing to undertake historical research in education” (p. 18). As for the latter, the tendency of mainstream historians has been to portray the field of educational history as, for the most part, moribund, and as having little to offer in either endeavor. This is a battering most historians of education will have endured to some extent. Only by taking account of these tendencies, the authors contend, will it be possible to understand why the field of educational history "has been conceived so tentatively in the past and how it might be developed in the future" (p. 26).

Chapter Three is entitled "History or Education?" Partially in answer to the problems posed in the previous chapter, it examines the tension between those who would use educational history to understand or to solve contemporary issues, and those 
who adhere to the liberal arts view of the study of history for history's sake. The chapter charts the development of the discipline through the international development of history as an academic endeavour and education as a field of study, prior to investigating the prospects for a "greater integration of the two traditions" (p. 5). Effective charts are employed to show the evolution of educational research and twentieth-century historiographical developments in the history of education in the English-speaking world. The argument presented here is that contesting approaches to the historical study of education for most of the past century have been largely influenced by the distinctive nature of education as an applied field and history as a discipline. At the end, it is suggested that because these separate traditions are in the process of breaking down and consolidating, this might offer some potential for assisting historians of education in their understanding of the reciprocal relation of education and society in different places and at different times.

Educational history has always set itself apart from the mainstream by its eclectic nature. Graduate seminars in educational "foundations," or the currently fashionable "policy studies," have most often included students from a variety of social science backgrounds. Chapter Four addresses this issue by examining a wide range of different social science theories and methodological concerns, and discusses how these might be applied to the history of education. Although the authors admit that sociological studies have tended to dominate the interdisciplinary nature of the field, and thus are well represented in the chapter, anthropological, psychological, and geographical works are also examined. By their own admission the chapter is not meant as an "exhaustive" survey, but merely an illustrative one. Obviously many other disciplines and sub-disciplines could potentially add to the mix. A relatively effective "Foucauldian" case study is presented to illustrate the interdisciplinary nature of post-modern approaches and the dangers inherent in their indiscriminate application.

The final three chapters examine more practical issues in the application of historical methodology to educational studies. 
Chapter Five deals with the range of published and easily accessible sources, both primary and secondary, that can be employed. Chapter Six, on the other hand, discusses less available sources, such as unpublished documents, visual and oral sources, plus some techniques used to gather and assess them. The chapter also discusses quantitative analysis in historical study and ways of bringing together different types of sources and analyses in educational history. Three very effective case studies are presented within these chapters that illustrate the gathering of particular sources, and some methodological issues surrounding their interpretation. Chapter Seven offers practical suggestions and discussion pertaining to the design and implementation of historical research projects in education. This includes a set of problems for analysis and some suggestions for future study.

Overall, Historical Research in Educational Settings makes a valuable contribution to the field. It is particularly well suited both to the graduate student in the social sciences hoping to use some aspect of historical inquiry as part of a thesis or dissertation project, and to the professional historian of education as both a potential teaching tool and as a reference guide. The text is clearly written and provides well-balanced analyses of the issues germane to interdisciplinary studies of this kind. One might quibble that the examples tend to orient themselves more towards Great Britain at the expense of other centres of study, and that the studies presented are aimed primarily at the English-speaking world; however, these limitations are acknowledged by the authors at the outset, and international studies are ably represented, albeit briefly.

Steven Boddington

University of Alberta

Athabasca University 